\title{
Review \\ Citrus Physiological and Molecular Response to Boron Stresses
}

\author{
Lin-Tong Yang ${ }^{1}{ }^{\oplus}$, Jun-Feng Pan ${ }^{1}$, Neng-Jing Hu ${ }^{1}$, Huan-Huan Chen ${ }^{1}$, Huan-Xin Jiang ${ }^{2}$, Yi-Bin Lu ${ }^{1}$ \\ and Li-Song Chen ${ }^{1, *(1)}$ \\ 1 College of Resources and Environment, Fujian Agriculture and Forestry University, Fuzhou 350002, China; \\ talstoy@163.com (L.-T.Y.); 1200807017@fafu.edu.cn (J.-F.P.); 3200831018@fafu.edu.cn (N.-J.H.); \\ huanhuanchen27@163.com (H.-H.C.); yibin.07@163.com (Y.-B.L.) \\ 2 College of Life Sciences, Fujian Agriculture and Forestry University, Fuzhou 350002, China; jianghx@163.com \\ * Correspondence: lisongchen2002@hotmail.com or lisongchen@fafu.edu.cn
}

check for updates

Citation: Yang, L.-T.; Pan, J.-F.; Hu, N.-J.; Chen, H.-H.; Jiang, H.-X.; Lu, Y.-B.; Chen, L.-S. Citrus Physiological and Molecular Response to Boron Stresses. Plants 2022, 11, 40. https:// doi.org/10.3390/plants11010040

Academic Editors: Juan J. CamachoCristóbal and Maria Reguera

Received: 22 November 2021 Accepted: 22 December 2021 Published: 23 December 2021

Publisher's Note: MDPI stays neutral with regard to jurisdictional claims in published maps and institutional affiliations.

Copyright: (c) 2021 by the authors. Licensee MDPI, Basel, Switzerland. This article is an open access article distributed under the terms and conditions of the Creative Commons Attribution (CC BY) license (https:// creativecommons.org/licenses/by/ $4.0 /)$.

\begin{abstract}
Since the essentiality of boron (B) to plant growth was reported nearly one century ago, the implication of B in physiological performance, productivity and quality of agricultural products, and the morphogenesis of apical meristem in plants has widely been studied. B stresses (B deficiency and toxicity), which lead to atrophy of canopy and deterioration of Citrus fruits, have long been discovered in citrus orchards. This paper reviews the research progress of B stresses on Citrus growth, photosynthesis, light use efficiency, nutrient absorption, organic acid metabolism, sugar metabolism and relocation, and antioxidant system. Moreover, the beneficial effects of B on plant stress tolerance and further research in this area were also discussed.
\end{abstract}

Keywords: Citrus; boron stress; B deficiency; B excess; tolerance

\section{Introduction}

Boron (B), an element essential for the growth, differentiation and reproduction of plant, exists in mineral such asborax, borosilicate, albite, brucite, colemanite, cristobalite, datolite and suanite, etc. B is widely distributed both in the Earth's crust (from $5 \mathrm{mg} \mathrm{kg}^{-1}$ in basalts to $100 \mathrm{mg} \mathrm{kg}^{-1}$ in shales), in topsoil(from $4 \mathrm{mg} \mathrm{kg}^{-1}$ to $145 \mathrm{mg} \mathrm{kg}^{-1}$ ) and in the ocean $\left(\sim 4.5 \mathrm{mg} \mathrm{L}^{-1}\right)$ as borate [1,2]. The well-established function of $\mathrm{B}$ in plants is to form the covalent bridge between pectin molecules by its cross-linking with pectic domain rhamnogalacturonan II(RG-II) in cell wall by the formation of RG-II-B diolester [3-5]. Such bridging decreases cell wall porosity, modifies cell wall biomechanical properties, plasticity and thickness, and regulates pectin assembly and plant development [3,6-10]. Borate ion and boric acid are highly soluble, hence B deficiency has been reported in both nature and agricultural practice, especially in areas with high temperature and high rainfalls [1]. The conventional method to solve B deficiency in field is to apply B-containing fertilizers. However, the heavy and long-term application of B fertilizer, mainly borax, and B-rich irrigation water, sewage sludge, or fly ash, frequently lead to B excess in agricultural practice [11]. Therefore, B deficiency and B excess could be both found in agricultural production.

B deficiency generally impairs cell elongation rather than cell division in growing tissues of plants. Typical B deficiency symptoms include inhibition of root cell elongation and pollen tube elongation, development of leaf interveinal chlorosis, enlargement, cracking and lignification of main lateral veins $[12,13]$. Since the first report of the essentiality of $B$ required for the normal grow than development of citrus by the use of sand cultures nearly one century ago [14], B deficiency is frequently observed in Citrus orchards, and is responsible for loss of productivity and poor fruit quality [15-17]. Under B-deficient conditions, the numbers of parenchyma cells in the vascular bundles of the leaf and fruit mesocarp increased significantly, whereas the lengths of xylem vessels in this tissue were both significantly lower than the corresponding values in control ones [18]. Anatomic analysis result showed that the cell wall was thicker and the inner vessel diameter was smaller in the 
B-deficient treatment than in the control ones. Such structural changes eventually reduced the function of the vessels in absorption and transportation of mineral nutrients, resulting in a limited nutrient supply and reduced growth of Poncirus trifoliata [19]. Sweet orange grafted on Swingle citrumelo sustained better growth by combining higher B absorption and root growth as well as better organization of xylem vessels under low B conditions. Under B toxicity, Swingle rootstock would improve water transport and favor plant growth by reducing anatomical and ultrastructural damage when compared with plants grafted on Sunki mandarin [20]. Despite the remarkable function of B on cell wall, B has been shown to function in the maintenance of plasma membrane stability and consequently regulate PM $\mathrm{H}^{+}$-ATPase activity generating a driving force for nutrient influx at the root level, and hence affecting nutrient uptake by Citrus roots [21]. B deficiency decreased the concentrations of chlorophylls (Chls) and carotenoids, $\mathrm{CO}_{2}$ assimilation, impaired photosynthetic electron transport chain, and significantly increased intercellular concentration and the concentrations of photosynthates such as glucose, fructose and starch in Citrus leaves [13,22]. Such altered carbohydrate metabolism inevitably affected other biological processes, such as amino acid metabolism, organic acid metabolism, and secondary metabolism. According to our previous study, B deficiency significantly upregulated the respiration, organic acid metabolism, amino acid and total phenolics biosynthesis in Citrus sinensis leaves, whereas downregulated these metabolisms in C. sinensis roots [23]. Similarly, B deficiency altered the key metabolites in glycolysis, amino acid metabolism and tricarboxylic acid (TCA) cycle, which was supposed to be associated with the inhibition of root elongation and the inflation of root tips in P. trifoliata under B starved condition [24]. Similar to B deficiency, B excess also decreased the $\mathrm{CO}_{2}$ assimilation and stomatal conductance, and increased intercellular $\mathrm{CO}_{2}$ concentration in Citrus leaves [25]. B toxicity led to alterations in pectin network crosslinking structure, destruction of cell wall integrity, chloroplast disintegration and plastoglobulus accumulation in $P$. trifoliata leaves, revealed by Fourier transform infrared spectroscopy (FTIR) and Transmission electronmicroscopy (TEM) analysis, respectively. B toxicity decreased the concentrations of proteins and cellulose, and increased carbohydrate concentration and starch grains in P. trifoliata leaves [26]. Both B deficiency and B excess could eventually lead to atrophy of canopy and deterioration of Citrus fruits [15].

In recent years, the molecular responses of plants to B deficiency or B excess were investigated to understand the adaptive mechanisms of plants to B stresses. For example, by using iTRAQ technique, a total of 164 up-regulated and 225 down-regulated proteins were identified in B-deficient C. sinensis roots [17]. Two-dimensional electrophoresis (2-DE) based MS approach reported that B excess increased the abundances of proteins involved in antioxidation, detoxification, proteolysis and cell transport in leaves and roots of $C$. sinensis, which might confer higher B-toxicity tolerance of $C$. sinensis than that of $C$. grandis $[27,28]$. Transcriptomic analysis showed that the expression levels of genes related to a broad biological processes from B uptake to plant development regulation and cell cycle, were altered by B stress in Citrus plants [17,29-34]. Furthermore, post-transcriptional regulation profile of gene expression by miRNAs was also investigated by Illumina sequencing in B-deficient C. sinensis leaves and roots [29,35].

Scion-rootstock combination studies demonstrated the different abilities of B uptake and root-to-shoot translocation existed among several key rootstocks, such as P. trifoliata, Swingle citrumelo, Carrizo citrange (CC), Cleopatra mandarin (CL), C. macrophylla (CM) and sour orange (SO), used in Citrus plantation [22,36-38]. Results obtained in these studies provided a scientific reference to select proper rootstock to cope with possible B deficiency or B excess conditions [20,21,39]. In addition, for ameliorating the adverse effects of B excess, some compounds, such as nitric oxide (NO), chitosan, methyl jasmonate (MeJA), and melatonin have been applied to plants [37]. Previous study showed that leaf $\mathrm{Ca}, \mathrm{Mg}$ and $\mathrm{B}$ concentrations decreased with $\mathrm{K}$ rates in sweet orange, indicating that interactions of $\mathrm{B}$ with other nutrients, such as $\mathrm{K}, \mathrm{Ca}$ and $\mathrm{Mg}$, were important for the nutrient management of orchards on different rootstock varieties $[40,41]$. Although the underlying mechanism was not fully elucidated, the application prospect of those elements or compounds in 
Citrus plantation could be expected in the future. Future efforts could pay attention to some biomarkers or key proteins such as CsNIP5;1, sorbitol-6-phosphate dehydrogenase, laccase 4 (LAC4), LAC7 and LAC17, which played vital roles in pectin biosynthesis, B transport and lignin biosynthesis, respectively, in Citrus plants cultivated in B problem locations [42-45].

B deficiency causes fruit drop and gum pockets in the peel. It sometimes occurs when farmers use only high-analytical grade fertilizers. Sinceit leaches readily, B should be applied every year either as a soil or foliar application [16]. Limited studies showed that soil application was more efficient than foliar application for the Citrus plants, which was important for best management strategies of B application. About 20 to $35 \%$ of B content in the new parts of orange tree came from plant reserves. B mobility within the plant was influenced by its nutritional status [46,47]. In contrast, management of B fertilizer and irrigation water, give a challenge to production practitioners in maintaining suitable B supply for Citrus trees. As a matter of fact, in China, B-toxicity occurs in some Citrus orchards. Up to $74.8 \%$ and $22.9 \%$ of pummelo (C. grandis) orchards in Pinghe, Zhangzhou, China, are excess in leaf B and soil water-soluble B, respectively [48]. This fact highlights the importance of understanding the role of B in Citrus tree growth and fruit production. In this paper, we reviewed the research progress of B stresses on Citrus growth, photosynthesis, light use efficiency, nutrient absorption, organic acid metabolism, sugar metabolism and relocation, and antioxidant system. Moreover, the beneficial effects of B in Citrus tress tolerance and further research in this area were also discussed.

\section{Physiological Responses to B Stress in Citrus}

Once absorbed by the roots, B is primarily transferred to mature leaves through xylem cells driven mainly by transpiration, except for some sugar alcohols (i.e., mannitol and sorbitol)-producing species such as Pyrus, Malus, Prunus, Allium and Brassica, many plants including Citrus, phloem mobility of B is limited [19,49]. Thus, the symptom of B deficiency was firstly developed in tender leaves and new shoot of Citrus plants, leading to dieback of terminal growth (Figure 1A,B). Along with the duration of B deficiency, the most apparent symptoms including spot-like chlorosis, coarsening, crimping, enlargement and cracking of leaf veins were observed in C. sinensis and C. grandis leaves [18,25].
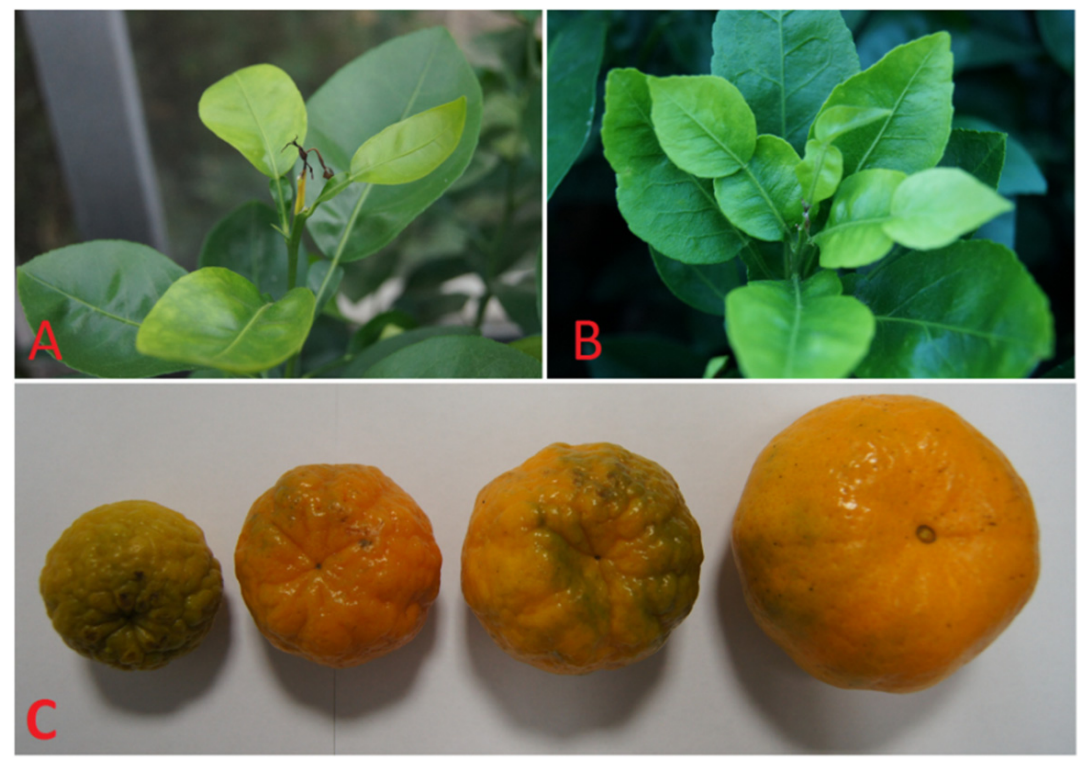

Figure 1. Symptoms of B deficiency in the leaves of $C$. sinensis $(\mathbf{A})$ and C. grandis (B), and the fruits of "Ponkan" (C. reticulata) $(\mathbf{C})$. Seedlings of $C$. sinensis $(\mathbf{A})$ and C. grandis $(\mathbf{B})$ were treated with $0 \mu \mathrm{M}$ $\mathrm{H}_{3} \mathrm{BO}_{3}$ for 15 weeks, respectively. Fruits of "Ponkan" were collected from Citrus orchard in Yongchun county, Quanzhou, Fujian province, China (C). 
It has been reported that B-deficiency leads to misshapen, small and hard fruit in C. sinensis $[15,50]$. There is limited information about the effects of B deficiency on Citrus fruits. According to available literatures and our observation, the symptom of B deficiency on Citrus fruits varied in different Citrus species, at least on the flavedo of fruits, for example, B deficient fruits developed asymmetrically in longitudinal sections, and brown secretions could be seen in the fruit peels of pummelo fruits [51]. During fruit expanding stage, B deficiency caused rough flavedo, small-size, chlorosis and abscission on "Ponkan" (C. reticulata) in Citrus orchard located in the southeast of Fujian province, China (Figure 1C).

As B has limited mobility and can only be supplied to growing tissues in the xylem, B uptake followed the passive water flux from roots to leaves and accumulated especially where leaf veins terminate [49]. Under B excess condition, tip yellowing of the lower part leaves, followed by marginal and interveinal chlorosis were observed in mature leaves. Along with the duration of $B$ excess, these chlorotic leaves became necrotic and fall off prematurely (Figure 2) [25].

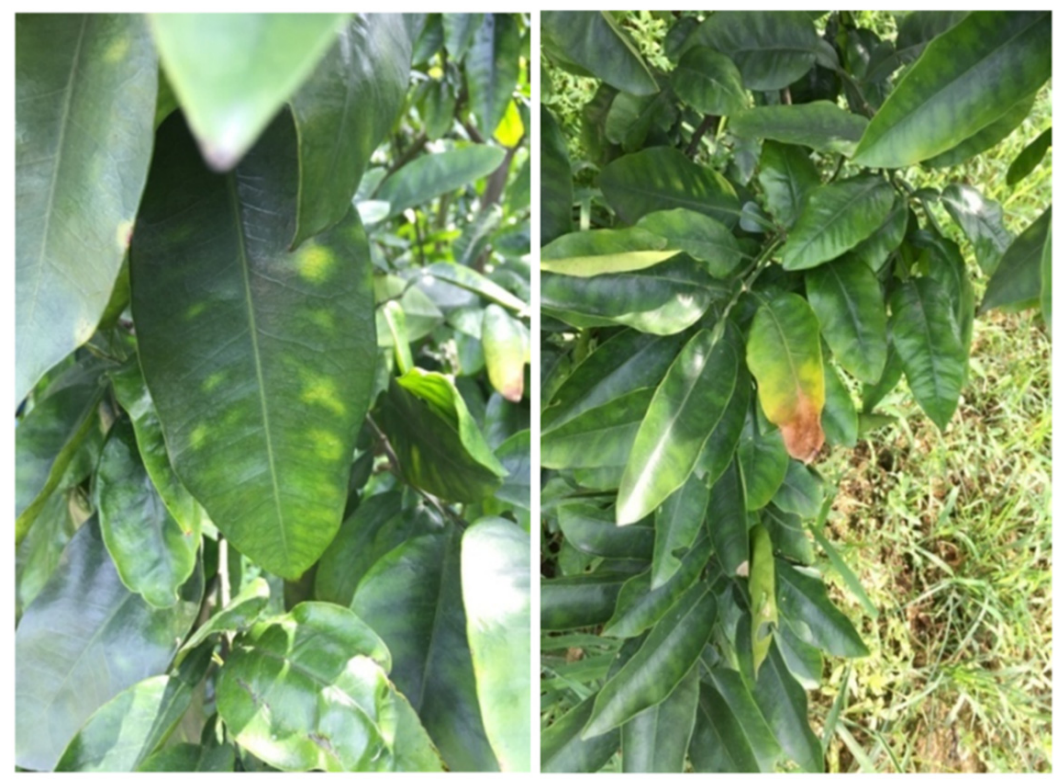

Figure 2. Leaf symptoms of B toxicity on pummelo (C. grandis) in field.

Both B deficiency and B excess could induce the degradation of Chls, leading to a compromised ability to process incident light by photosynthesis in plants, which were eventually more susceptible to oxidative damage $[52,53]$. B deficiency decreased $\mathrm{Chl} a, \mathrm{Chl} b$ and carotenoid concentrations, but increased the ratio of $\mathrm{Chl} a / \mathrm{Chl} b$ in $C$. sinensis leaves [13]. Chl $a$ fluorescence (OJIP) transients from B-deficient Citrus leaves displayed a positive Land K-bands, an increased initial fluorescence $\left(\mathrm{F}_{\mathrm{O}}\right)$ and a decreased maximum quantum yield of primary photochemistry $\left(\mathrm{F}_{\mathrm{v}} / \mathrm{F}_{\mathrm{m}}\right)$, meaning that the PSII units are less grouped (stable) or less energy is being exchanged between independent PS II units, and that the oxygen-evolving complex (OEC) was damaged in these leaves. Moreover, B-deficiencyinduced photoinhibition of PSII led to reduced use of light energy in electron transport and increased accumulation of excess light energy, which eventually elevated the production and accumulation of reactive oxygen species (ROS) [13,25]. In fact, B-deficiency-induced impairment of photosynthetic electron transport and reduction of $\mathrm{CO}_{2}$ assimilation might be caused by feedback inhibition, as $\mathrm{B}$ deficiency significantly increased intercellular $\mathrm{CO}_{2}$ concentration and the concentrations of photosynthates such as glucose, fructose and starch in Citrus leaves (Figure 3) [13,25]. Although, the primary mechanisms of B's roles in photosynthesis are unknown, B could impact the biological functions of internal membranes in chloroplast by disturbing thylakoid electron transport and the energy conversion rate, resulting in photoinhibition [54]. Similarly, the repression of photosynthetic enzymes, such 
as ribulose-1,5-bisphosphate carboxylase/oxygenase (Rubisco), NADP-glyceraldehyde3-phosphate dehydrogenase (NADP-GAPDH) and stromal fructose-1,6-bisphosphatase (FBPase), were also observed in B-deficient Citrus leaves [13]. B-deficiency significantly reduced the concentrations of Chls and carotenoids, and increased the concentrations of total soluble sugar and lignin in 'Newhall' navel orange. Moreover, B-deficiency substantially down-regulated the expression levels of photosynthesis-related genes, and induced the expression levels of genes related to Chl decomposition, glucose synthesis and lignin synthesis, but significantly inhibited the expression of carotenoid synthesis-related genes in 'Newhall' navel orange [22].

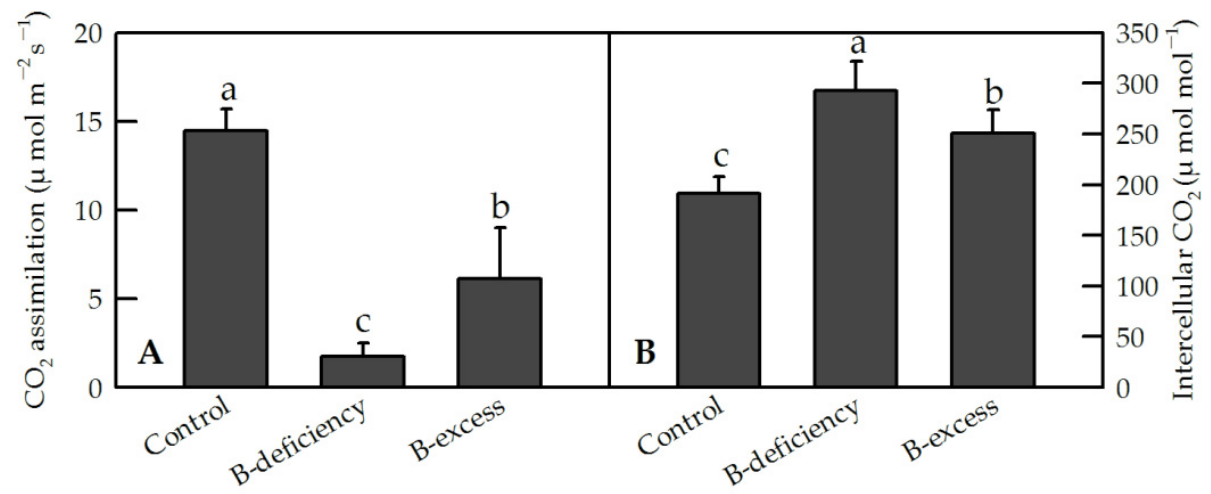

Figure 3. Effects of $\mathrm{B}$ deficiency and $\mathrm{B}$ excess on leaf $\mathrm{CO}_{2}$ assimilation (A) and intercellular $\mathrm{CO}_{2}$ concentration $(\mathbf{B})$ in $C$. sinensis. Seedlings of $C$. sinensis were treated with 10 (Control), 0 (B-deficiency) and $400 \mu \mathrm{M}$ (B-excess) $\mathrm{H}_{3} \mathrm{BO}_{3}$ for 15 weeks, respectively. Bars represent means $\pm \mathrm{SD}(n=4)$. Differences among the treatments were analyzed by ANOVA. Different letters above the bars indicate a significant difference at $p<0.05$.

On the other hand, $\mathrm{B}$ toxicity decreased $\mathrm{CO}_{2}$ assimilation and stomatal conductance, but had no impact on intercellular $\mathrm{CO}_{2}$ concentration. According to the stomatal limited theory in photosynthesis, B-toxicity-induced decrease in $\mathrm{CO}_{2}$ assimilation of $C$. sinensis and C. Grandis was mainly caused by non-stomatal factors. JIP test indicated that the damage of photosynthetic electron transport induced by B stress was more severe by B toxicity than by B deficiency in C. grandis leaves [25]. In addition, the typical B-toxic symptom only occurred in B-toxic C. grandis leaves, and no visible symptoms were observed in B-toxic C. sinensis leaves except for very few seedlings [27].

B-toxicity-induced decreases of seedlings growth, leaf $\mathrm{CO}_{2}$ assimilation, pigments and total soluble protein concentrations and increase of leaf malondialdehyde (MDA) concentration were less pronounced in $C$. sinensis than in $C$. grandis seedlings. These results draw the fact that $\boldsymbol{C}$. sinensis is more tolerant to B-toxicity than $C$. grandis $[25,27,31,55]$. Sweet orange scions grafted on Swingle were more tolerant to both B deficiency and toxicity than those on Sunki, as revealed by higher shoot and root growth, and less reductions of both whole plant leaf-specific hydraulic conductance and leaf $\mathrm{CO}_{2}$ assimilation [20]. Moreover, Huang et al. [55] reported that leaves from B-toxic $C$. grandis seedling had higher free B and lower bound B as compared with those from C. sinensis. B toxicity led to irregular cell wall thickening in leaf cortex cells and phloem tissue of both C. grandis and C. sinensis leaves, but exocytosis only occurred in $C$. sinensis. In contrast, B toxicity induced programmed cell death (PCD) of phloem tissue was only observed in C. grandis leaves. They concluded that the higher B-toxicity tolerance of $C$. sinensis than $C$. grandis could be attributed to the lower leaf free- $\mathrm{B}$ concentration and higher bound $\mathrm{B}$ concentration in the former ones [55].

ROS, including singlet oxygen $\left({ }^{1} \mathrm{O}_{2}\right)$, superoxide anion $\left(\mathrm{O}_{2}{ }^{--}\right)$, hydrogen peroxide $\left(\mathrm{H}_{2} \mathrm{O}_{2}\right)$, and hydroxyl radical ( $\left.\mathrm{HO}\right)$, are partially reduced or excited forms of atmospheric oxygen, which can be produced in nearly every sub-cellular compartment. They are the unavoidable toxic byproducts of aerobic metabolism, and function as signaling molecules as well $[56,57]$. Increments of ROS production have been found in Citrus plants encountering 
various environment stresses including phosphorus deficiency, aluminum toxicity, magnesium deficiency, manganese toxicity and B stresses [28,58-62]. As a strategic response, a large group of antioxidant molecules, such as amino acids, carotenoids, flavonoids, ascorbate (ASC) and reduced glutathione (GSH), and a series of antioxidant enzymes, for example, superoxide dismutase (SOD; EC 1.15.1.1), catalase (CAT; EC 1.11.1.6), ASC peroxidase (APX; EC 1.11.1.11), monodehydroascorbate reductase (MDAR; EC 1.6.5.4), dehydroascorbate reductase (DHAR; EC 1.8.5.1) and glutathione reductase (GR; EC 1.6.4.2), were found in plants [57]. Characterized by reacting rapidly with $\mathrm{H}_{2} \mathrm{O}_{2}$ and their oxidized forms being regenerated by high-capacity reductases and associated systems, ASC and GSH are key players in antioxidant system and measured as represent of antioxidant compounds in many circumstances [63]. Both ASC and GSH concentrations were increased by B-deficiency but were decreased by B-excess in C. sinensis leaves. B-deficient leaves had higher SOD, APX, MDAR, DHAR and GR activities, lower CAT activity. B excess leaves had higher SOD, APX, and GR activities, lower MDAR, DHAR and CAT activities. $B$ deficiency significantly increased $\mathrm{O}_{2}{ }^{--}$generation, MDA concentration and electrolyte leakage in C. sinensis leaves. B-deficient leaves displayed higher or similar activities of antioxidant enzymes compared to B-excess ones. Although both B-deficient and -excess leaves remain high in activity of antioxidant enzymes, the up-regulated antioxidant system could not provide sufficient protection to these leaves against oxidative damage, as MDA concentration was simultaneously increased by B deficiency and B excess [13,25]. Similarly, B deficiency elevated $\mathrm{O}_{2} \cdot{ }^{\cdot-}$ and $\mathrm{H}_{2} \mathrm{O}_{2}$ generation and electrolyte leakage in tea plants. The activities of APX, CAT, peroxidase (POD; EC 1.11.1.7) and SOD were increased in B deficient plants. Simultaneously, transcripts of the antioxidant enzymes were up regulated under $B$ deficiency. By and large, the authors concluded that B deficiency intensifies ROS generation, but the antioxidant system could not provide for an adequate protection from oxidative damage, as the concentration of MDA in tea leaves was increased by B deficiency [64]. Simón-Grao et al. [65] investigated the responses of different Citrus rootstock to B excess. $\mathrm{SO}$ rootstock proved to be more tolerant to $\mathrm{B}$ toxicity than $\mathrm{CC}$ rootstock. Such result was attributed to less accumulation of $\mathrm{B}$ in $\mathrm{SO}$ leaves, as its roots might sense the external $\mathrm{B}$ concentration and restrict the uptake and relocation of $\mathrm{B}$ into upwards the shoots. In addition, $\mathrm{SO}$ was suggested to encounter B-toxicity-induced oxidative stress by enhancing its antioxidant system, including higher activity of APX and SOD, and higher accumulation of quaternary ammonium compounds (QACs), when compared to CC. However, the sudden increment of ROS production observed in Citrus leaves and roots under B deficiency and B excess conditions might be of great biological benefit, as the signaling advantage of ROS is their close connection to cellular homeostasis and metabolism. Almost any change in intracellular homeostasis may lead to a change in the steady-state level of ROS in a specific compartments [57].

Highly mobility of B from mature leaves to tender leaves and florets, and the existence of B compounds in extra floral nectar and the phloem sap, validated that sugar alcohols, such as sorbitol and mannitol, could facilitate the pholem mobility in sorbitol-rich species within Prunus, Pyrus, and Malus [31,33,37,42]. Gene-modified enhancement of sorbitol biosynthesis accompanied by an increased $B$ concentration indicated that sugar alcohol can result in increased B uptake in plants $[37,42]$. So far, the metabolism of sugar alcohols in citrus rootstocks was still unknown.

Several studies showed that Citrus rootstocks differed in physiological responses under varied B conditions [22,36,65-67]. 'Newhall' orange (C. sinensis) scion grafted on $\mathrm{CC}$ showed higher tolerance of long-term B deficiency than that grafted on trifoliate orange, which was demonstrated by the fact that low-B decreased leaf $\mathrm{CO}_{2}$ assimilation, stomatal conductance and transpiration rate but increased intercellular $\mathrm{CO}_{2}$ concentration in 'Newhall' orange leaves. Furthermore, there existed a fine-tuning distribution of B in citrus roots and shoots, as B in scion and rootstock showed a restricted translocation of B to shoots under conditions of limited B availability [66]. Subsequent study found that different regulation of metabolic pathways about chlorophyll decomposition, glucose 
synthesis, lignin and carotenoid synthesis might be of great influence on the distinct responses of 'Newhall' orange scion grafted on CC and trifoliate orange [22]. Moreover, B was preferentially transferred to upper-younger leaves to support their growth, implying an unveiled mechanism in sensing and balancing the B status between roots and shoots in Citrus plants [66].

In Citrus plants, not only did total B content affect and determine plant growth and development, the speciation of B in Citrus could also influence the physiological responses in different scion-rootstock combinations. For instance, the ratio of semi-bound $B$ to free B (semi-bound B/free B) was higher in citrange-grafted 'Newhall' navel orange than in trifoliate orange-grafted plants under the same B supply level. These results demonstrated that citrange-grafted plants had a higher B utilization efficiency than that grafted on trifoliate orange [67]. Moreover, Citrus plants could strategically regulate the mineral nutrient concentrations in responding to the abnormal B status. For example, Verna lemon trees grafted on $\mathrm{CM}$ rootstock had a higher concentration of nitrogen $(\mathrm{N})$ in the leaves and roots than those grafted on $\mathrm{CC}, \mathrm{CL}, \mathrm{SO}$. According to previous study that improving $\mathrm{N}$ fertilization can alleviate $\mathrm{B}$ stress by enhancing the antioxidant system in lentils and barley, the increase in $\mathrm{N}$ concentration might have helped to mitigate the adverse effects of a higher concentration of $\mathrm{B}$ in the leaves and roots of Verna lemon scions $[36,68]$. However, investigation of the responses of different rootstock seedlings under B excess revealed that $\mathrm{SO}$ rootstock was the most tolerant species to $\mathrm{B}$ excess, while $\mathrm{CC}$ was the most sensitive ones [65]. The possible mechanism underlying the higher tolerance of SO to B excess might be attributed to the restriction of the uptake and transport of $B$ towards the aerial part, and higher activities of antioxidant enzymes, such as APX and SOD [65]. These results indicated that interaction of scion and rootstock might implicate in transportation and re-distribution of $\mathrm{B}$, and physiological responses of scion under $\mathrm{B}$ stress conditions. In conclusion, both low $\mathrm{B}$ and $\mathrm{B}$ excess led to decomposition of $\mathrm{Chls}$, decreased $\mathrm{CO}_{2}$ assimilation, provoked ROS production and ROS scavenging system, and eventually inhibited Citrus tree growth and fruit production.

\section{Molecular Responses to B Stress in Citrus}

In recent decade, in order to better understanding the adaptive mechanisms of plants to $B$ stresses, many efforts have been made to investigate the molecular response of plants to $\mathrm{B}$ nutrition disorder. Evidence shows that the expression levels of genes related to B uptake and translocation, carbohydrate and energy metabolism, cell wall and membranes, $\mathrm{N}$ metabolism, stress responses, nucleic acid metabolism, signal transduction, development regulation and cell cycle, were altered by B stresses in Citrus plants $[17,29,33,34]$.

By using iTRAQ technique, a total of 164 up-regulated and 225 down-regulated proteins were identified in B-deficient $C$. sinensis roots. These differentially abundant proteins were grouped into the following functional categories: protein metabolism, nucleic acid metabolism, carbohydrate metabolism, cellular transport, cell wall and cytoskeleton metabolism, signal transduction, stress responses, and lipid metabolism [17]. The adaptive responses of Citrus roots to B deficiency might include several altered physiological processes, such as decreasing root respiration, improving the total ability to scavenge ROS, and enhancing cell transport. As we mentioned above that B stresses disturbed ROS equilibrium in cellular level in Citrus, B deficiency increased the abundance of 31 proteins related to antioxidant system including SOD, POD, MDAR, aldehyde dehydrogenase (ALDH), CBS family protein, hemoglobin1 and HSPs/chaperones in C. sinensis roots [17]. B deficiency also induced oxidative stress in $C$. grandis roots as the abundances of many antioxidant proteins such as small ubiquitin-like modifier, peroxiredoxin, peroxidase 2, glutathione peroxidase, methionine sulfoxide reductase, cystatin B, dehydrin family protein, MLP-like protein and antioxidant 1 were increased [4].

In order to gain the comprehensive view of transcriptomic profile in Citrus plants under low B and B excess conditions, the cDNA-AFLP technique was used to investigate the differentially expressed genes and their related biological processes of $C$. grandis 
and/or C. sinensis under B stress [30-32]. A total of 82 and 83 differentially expressed transcript-derived fragments (TDFs) from leaves and roots were isolated in $C$. sinensis under B deficiency, respectively. These TDFs were mainly involved in amino acid metabolism, energy metabolism, nucleic acid metabolism, cell transport, signal transduction, and stress response. Most of the TDFs associated with signal transduction and stress response were down-regulated in C. sinensis roots, but up-regulated in leaves. TDFs related to protein ubiquitination and proteolysis were mostly induced in B-deficient leaves. These results proposed a new insight into the different adaptive mechanisms of $C$. sinensis roots and leaves to $B$ deficiency at the transcriptional level [30]. In another study, cDNA-AFLP analysis showed that the variation of transcriptomic profile was larger in C. grandis than in C. sinensis, as 132 and 68 differentially expressed TDFs were successfully isolated in B-toxic C. grandis and $C$. sinensis, respectively. The differentially expressed TDFs were involved in broad physiological processes from signal transduction and photosynthesis to morphological reconstruction. The authors attributed the higher B-toxicity tolerance of $C$. sinensis to higher expression levels of genes involved in photosynthesis, light utilization and ROS scavenging ability in leaves, which preventing them from photo-oxidative damage [31]. Similar result was also found in Citrus roots, where 72 and 110 differentially expressed TDFs were isolated from excess B-treated C. sinensis and C. grandis roots, respectively. The higher B-toxicity tolerance of $C$. sinensis could be explained by the differentially expressed genes involved in root hair development, antioxidant system, $\mathrm{Ca}^{2+}$-mediated signal transduction, and lipid metabolism between $C$. sinensis and C. grandis roots under B excess condition [32]. miRNAs have been identified as important post-transcriptional regulators of gene expression in plants. From this point, Lu et al. [29,35] used Illumina sequencing to investigate the effects of B deficiency on the expression patterns of miRNAs in C. sinensis leaves and roots. A total of 172 and 134 differentially expressed miRNAs were identified in B-deficient C. sinensis leaves and roots, respectively. The response of miRNA profile to B deficiency which contributes to low-B tolerance in $C$. sinensis leaves, might include several aspects: (a) the attenuation of plant growth and development by repressing auxin signaling (miR393, miR160 and miR3946); (b) maintaining leaf phenotype and enhancing the stress tolerance (miR159, miR782, and miR3946, etc.); (c) activation of the stress responses and antioxidant system (miR164, miR6260 and miR5929, etc.); and (d) lowering B export (miR5037) [35]. In contrast, the possible roles of miRNAs in the tolerance of roots to B deficiency could be summarized as: (a) inactivating ROS signaling and scavenging (miR474, miR782 and miR843); (b) increasing lateral root number (miR5023); (c) enhancing cell transport (miR830, miR5266 and miR3465); and (d) improving osmoprotection (miR474) [29]. Furthermore, Sang et al. $[27,28]$ investigated the differentially expressed protein profiles of two Citrus species differing in B-toxicity tolerance, and found that B excess increased the abundances of protein species involved in antioxidation, detoxification, proteolysis and cell transport in leaves and roots of $C$. sinensis more than those of $C$. grandis. Although B excess decreased photosynthesis rate in both $C$. sinensis and $C$. grandis, various differentially abundant proteins in leaves conferred a better maintenance of energy homeostasis to C. sinensis [27]. In roots, the differentially abundant proteins related to the methyl cycle, the cell wall and cytoskeleton integrity, and the detoxification of the ROS and other toxic compounds such as aldehydes, might be responsible for the higher B-toxicity tolerance of $C$. sinensis [28].

For ameliorating the adverse effects of $\mathrm{B}$ disorder, some elements or compounds have been applied to plants. For instance, application of fertilizers containing $\mathrm{Si}, \mathrm{Ca}$, and $\mathrm{Zn}$, could facilitate photosynthesis of plants grown in excess B [37]. The application of NO, chitosan, MeJA, melatonin and 28-homobrassinolide (HBL) were also reported to improve plant growth and photosynthesis related performance parameters, such as stomatal conductance, net photosynthetic rate, and intercellular $\mathrm{CO}_{2}$ concentrationin several crops (Artemisia annua, cucumber, and Vigna radiata) under B-toxic conditions [37]. Although the underlying mechanisms were not fully elucidated, the application prospect of those elements or compounds in Citrus plantation, especially those located in arid and semi-arid area, could be expected in the future. For assistant selection breeding, future efforts could 
pay attention to some biomarkers or key proteins such as trans-1, 2-diaminocyclohexane- $\mathrm{N}$, $\mathrm{N}, \mathrm{N}, \mathrm{N}$-tetraacetic acid (CDTA)-soluble pectin, sorbitol-6-phosphate dehydrogenase, and LAC7, which played vital roles in pectin biosynthesis, B transport and lignin biosynthesis in Citrus plants under B stress, respectively [18,42,43]. More recently, Huang et al. [45] reported that B-toxicity-induced up-regulation of CsiLAC4 due to the downregulation of miR397 led to the lignification of the xylem cell walls and the restriction of B flow from xylem vessels to the phloem in Citrus.

\section{Ameliorative Roles of B on Abiotic Stresses in Citrus}

The prominent role of B in plant cells determined the compact and complex structure of cell wall, and cell wall played as the primary barrier to harmful microorganisms and toxic elements $[3,68]$. In other crops, for example, in rice and rapeseed, application of $\mathrm{B}$ was reported to alleviate cadmium toxicity by decreasing organelle $\mathrm{Cd}$ concentration and increasing $\mathrm{Cd}$ adsorption on the cell wall, which eventually restricted the entry of $\mathrm{Cd}$ ions into the cells and protecting plants from oxidative stress in the roots and leaves of rice [69-71]. Interestingly, B could increase root pectin biosynthesis and decrease the degradation of pectin by downregulating the activity of pectinase activity, in addition, the methylation of pectin was also decreased by the higher methylesterase activity to increase the chelation site of $\mathrm{Cd}$ onto the cell walls in rapeseed [72]. Apart from increasing $\mathrm{Cd}$ being bound to the cell walls and decreasing Cd entering into organelle, elevating B supply could alleviate $\mathrm{Cd}$-induced oxidative stress by increasing the activity of the major antioxidant enzymes, SOD, POD, and CAT [71]. Those results implied that the alleviative effects of B in $\mathrm{Cd}$ toxicity not only dependent on regulating constituent and properties of cell wall to facilitate $\mathrm{Cd}$ binding, but also include regulating the cellular biological process to flexibly encounter the adverse effects of $\mathrm{Cd}$ toxicity and subsequent physiological disorders [71-73]. Similarly, the alleviation of Al-induced inhibition in plant growth and development due to elevated B concentration in nutrient solution has been observed in many higher plants, including pea [74], flax [75] and Citrus [76-78].

Al toxicity and B deficiency are two major factors limiting crop production in tropical and subtropical areas. Our previous study showed that elevating B supply can alleviate the Al-induced inhibition of growth in C. grandis [76-78]. By using 2-DE based MALDITOF/TOF-MS method, sixty-one differentially abundant proteins in Citrus roots in response to $\mathrm{B}-\mathrm{Al}$ interactions were successfully identified [76]. These differentially abundant proteins mainly involved in modification of cell wall, turnover of dysfunctional proteins, stress response, cellular biological regulation and signal transduction. Some proteins including cell division protein 48 (CDC48), calreticulin and phospholipase, might be involved in the downstream signaling of the beneficial effects of B in alleviating Al stress in Citrus plants.

\section{Conclusions}

Due to the miniscule requirement of B in crop growth, the essentiality of B in agricultural production is frequently ignored by the production practitioners. The small range of B suitability makes the inappropriate application of B fertilizer a measure at fault leading to B toxicity. Thus, B deficiency and B excess might simultaneously exist at some area. Management of B nutrition became a crucial process, especially in fruit-based industry including Citrus production. Visible symptoms of B deficiency and excess include dieback of growing sites, leaf chlorosis and poor performance of photosynthesis system. Physiological analysis showed that B disorders induced the alternation of primary and secondary metabolisms, such as constituent of cell wall, nutrient absorption, antioxidant systems, carbohydrate and energy metabolism. Proteomic and transcriptomic studies showed that B disorder affected the whole process of Citrus development from gene transcription to the final morphogenesis. Different scion-rootstock combinations revealed an apparent distinction of B distribution between roots and shoots, and among different Citrus species. Future study should focus on the mechanisms underlying the transportation and relocation of B in Citrus, especially the metabolism of the companion compounds of B transport, such 
as sugar alcohols. Furthermore, except for regulating the structure and content of cell wall constituents, the physiological functions of B in other biological processes should also be investigated to better boost the sustainable and high-quality Citrus production in the future study.

Author Contributions: Conceptualization, L.-T.Y. and L.-S.C.; software, J.-F.P. and N.-J.H.; methodology, H.-H.C.; investigation, H.-X.J. and Y.-B.L.; writing-original draft preparation, L.-T.Y. and H.-H.C.; writing-review and editing, L.-T.Y. and L.-S.C.; funding acquisition, L.-T.Y. and L.-S.C. All authors have read and agreed to the published version of the manuscript.

Funding: This research was funded by the Provincial Natural Science Foundation of Fujian, China (No. 2021J01122) and the National Natural Science Foundation of China (32072511).

Institutional Review Board Statement: Not applicable.

Informed Consent Statement: Not applicable.

Data Availability Statement: Not applicable.

Conflicts of Interest: The authors declare no conflict of interest. The funders had no role in the design of the study; in the collection, analyses, or interpretation of data; in the writing of the manuscript, or in the decision to publish the results.

\section{References}

1. Shorrocks, V.M. The occurrence and correction of boron deficiency. Plant Soil 1997, 193, 121-148. [CrossRef]

2. Bolaños, L.; Lukaszewski, K.; Bonilla, I.; Blevins, D. Why boron? Plant Physiol. Biochem. 2004, 42, 907-912. [CrossRef] [PubMed]

3. Chormova, D.; Fry, S.C. Boron bridging of rhamnogalacturonan-II is promoted in vitro by cationic chaperones, including polyhistidine and wall glycoproteins. New Phytol. 2016, 209, 241-251. [CrossRef]

4. Yang, L.T.; Lu, Y.B.; Zhang, Y.; Guo, P.; Chen, L.S. Proteomic profile of Citrus grandis roots under long-term boron-deficiency revealed by iTRAQ. Trees 2016, 30, 1057-1071. [CrossRef]

5. Reguera, M.; Abreu, I.; Brewin, N.J.; Bonilla, I.; Bolaños, L. Borate promotes the formation of a complex between legume AGP-extensin and Rhamnogalacturonan II and enhances production of Rhizobium capsular polysaccharide during infection thread development in Pisum sativum symbiotic root nodules. Plant Cell Environ. 2010, 33, 2112-2120. [CrossRef] [PubMed]

6. Camacho-Cristóbal, J.J.; Navarro-Gochicoa, M.T.; Rexach, J.; González-Fontes, A.; Herrera-Rodríguez, M.B. Plant response to boron deficiency and boron use efficiency in crop plants. In Plant Micronutrient Use Efficiency, 1st ed.; Hossain, M.A., Kamiya, T., Burritt, D.J., Phan Tran, L.S., Fujiwara, T., Eds.; Academic Press: London, UK, 2018; pp. 109-121.

7. Dong, X.; Lu, X.; Wu, X.; Liu, G.; Yan, L.; Muhammad, R.; Wu, L.; Jiang, C. Changes in chemical composition and structure of root cell wall of citrus rootstock seedlings in response to boron deficiency by FTIR spectroscopy. J. Hortic. Sci. Biotechnol. 2018, 93, 150-158. [CrossRef]

8. Funakawa, H.; Miwa, K. Synthesis of borate cross-linked rhamnogalacturonan II. Front. Plant Sci. 2015, 6, 223. [CrossRef]

9. Poza-Viejo, L.; Abreu, I.; Allauca, P.; Bonilla, I.; Bolaños, L.; Reguera, M. Boron deficiency inhibits root growth by controlling meristem activity under cytokinin regulation. Plant Sci. 2018, 270, 176-189. [CrossRef]

10. Camacho-Cristóbal, J.J.; Rexach, J.; González-Fontes, A. Boron in plants: Deficiency and toxicity. J. Integr. Plant Biol. 2008, 50, 1247-1255. [CrossRef]

11. Nable, R.O.; Bañuelos, G.S.; Paull, J.G. Boron toxicity. Plant Soil 1997, 193, 181-198. [CrossRef]

12. Dell, B.; Huang, L. Physiological response of plants to low boron. Plant Soil 1997, 193, 103-120. [CrossRef]

13. Han, S.; Chen, L.S.; Jiang, H.X.; Smith, B.R.; Yang, L.T.; Xie, C.Y. Boron deficiency decreases growth and photosynthesis, and increases starch and hexoses in leaves of citrus seedlings. J. Plant Physiol. 2008, 165, 1331-1341. [CrossRef]

14. Haas, A.R.C. Boron as an essential element for healthy growth of citrus. Bot. Gaz. 1930, 89, 410-413. [CrossRef]

15. Chen, L.S.; Han, S.; Qi, Y.P.; Yang, L.T. Boron stresses and tolerance in citrus. Afr. J. Biotechnol. 2012, $22,5961-5969$.

16. Obreza, T.; Morgan, K.T.; Futch, S.H. General soil fertility and citrus tree nutrition. In Nutrition of Florida Citrus Trees, 2nd ed.; Obreza, T.A., Morgan, K.T., Eds.; University of Florida/IFAS Extension Office: Gainesville, FL, USA, 2008 ; pp. 16-23.

17. Yang, L.T.; Qi, Y.P.; Lu, Y.B.; Guo, P.; Sang, W.; Feng, H.; Zhang, H.X.; Chen, L.S. iTRAQ protein profile analysis of Citrus sinensis roots in response to long-term boron-deficiency. J. Proteom. 2013, 93, 179-206. [CrossRef] [PubMed]

18. Liu, G.D.; Wang, R.D.; Liu, L.C.; Wu, L.S.; Jiang, C.C. Cellular boron allocation and pectin composition in two citrus rootstock seedlings differing in boron-deficiency response. Plant Soil 2013, 370, 555-565. [CrossRef]

19. Li, M.; Li, Q.; Wang, H.; Sheng, O.; Peng, S.A. Boron deficiency affects root vessel anatomy and mineral nutrient allocation of Poncirus trifoliata (L.) Raf. Acta Physiol. Plant 2016, 38, 86.

20. Mesquita, G.L.; Zambrosi, F.C.B.; Tanaka, F.A.O.; Boaretto, R.M.; Quaggio, J.A.; Ribeiro, R.V.; Mattos, D., Jr. Anatomical and physiological responses of Citrus trees to varying boron availability are dependent on rootstock. Front. Plant Sci. 2016, 7, 224. [CrossRef] 
21. Ferreira, G.A.; Hippler, F.W.R.; Prado, L.A.d.S.; Rima, J.A.H.; Boaretto, R.M.; Quaggio, J.A.; Façanha, A.R.; Mattos, D., Jr. Boron modulates the plasma membrane $\mathrm{H}^{+}$-ATPase activity affecting nutrient uptake of Citrus trees. Ann. Appl. Biol. 2021, 178, 293-303. [CrossRef]

22. Liu, X.; Zhang, J.W.; Guo, L.X.; Liu, Y.Z.; Jin, L.F.; Hussain, S.B.; Du, W.; Deng, Z.; Peng, S.A. Transcriptome changes associated with boron deficiency in leaves of two citrus scion-rootstock combinations. Front. Plant Sci. 2017, 8, 317. [CrossRef]

23. Lu, Y.B.; Yang, L.T.; Li, Y.; Xu, J.; Liao, T.T.; Chen, Y.B.; Chen, L.S. Effects of boron deficiency on major metabolites, key enzymes and gas exchange in leaves and roots of Citrus sinensis seedlings. Tree Physiol. 2014, 34, 608-618. [CrossRef] [PubMed]

24. Wu, X.; Liu, G.; Riaz, M.; Yan, L.; Jiang, C. Metabolic changes in roots of trifoliate orange [Poncirus trifoliate (L.) Raf.] as induced by different treatments of boron deficiency and resupply. Plant Soil 2019, 434, 217-229. [CrossRef]

25. Han, S.; Tang, N.; Jiang, H.X.; Yang, L.T.; Li, Y.; Chen, L.S. $\mathrm{CO}_{2}$ assimilation, photosystem II photochemistry, carbohydrate metabolism and antioxidant system of citrus leaves in response to boron stress. Plant Sci. 2009, 176, 143-153. [CrossRef]

26. Wu, X.; Lu, X.; Riaz, M.; Yan, L.; Jiang, C. Boron toxicity induced specific changes of cell ultrastructure and architecture of components in leaf center and tip of trifoliate orange [Poncirus trifoliata (L.) Raf.]. J. Environ. Manag. 2019, 246, 426-433. [CrossRef] [PubMed]

27. Sang, W.; Huang, Z.R.; Qi, Y.P.; Yang, L.T.; Guo, P.; Chen, L.S. An investigation of boron-toxicity in leaves of two citrus species differing in boron-tolerance using comparative proteomics. J. Proteom. 2015, 123, 128-146. [CrossRef]

28. Sang, W.; Huang, Z.R.; Yang, L.T.; Guo, P.; Ye, X.; Chen, L.S. Effects of high toxic boron concentration on protein profiles in roots of two citrus species differing in boron-tolerance revealed by a 2-DE based MS approach. Front. Plant Sci. 2017, 8, 180. [CrossRef]

29. Lu, Y.B.; Yang, L.T.; Qi, Y.P.; Li, Y.; Li, Z.; Chen, Y.B.; Huang, Z.R.; Chen, L.S. Identification of boron-deficiency-responsive microRNAs in Citrus sinensis roots by Illumina sequencing. BMC Plant Biol. 2014, 14, 123. [CrossRef]

30. Lu, Y.B.; Qi, Y.P.; Lee, J.; Guo, P.; Ye, X.; Jia, M.Y.; Li, M.L.; Chen, L.S. Long-term boron-deficiency-responsive genes revealed by cDNA-AFLP differ between Citrus sinensis roots and leaves. Front. Plant Sci. 2015, 6, 271. [CrossRef] [PubMed]

31. Guo, P.; Qi, Y.P.; Yang, L.T.; Ye, X.; Jiang, H.X.; Huang, J.H.; Chen, L.S. cDNA-AFLP analysis reveals the adaptive responses of citrus to long-term boron-toxicity. BMC Plant Biol. 2014, 14, 284. [CrossRef]

32. Guo, P.; Qi, Y.P.; Yang, L.T.; Ye, X.; Huang, J.H.; Chen, L.S. Long-term boron-excess-induced alterations of gene profiles in roots of two citrus species differing in boron-tolerance revealed by cDNA-AFLP. Front. Plant Sci. 2016, 7, 898. [CrossRef] [PubMed]

33. Reid, R. Understanding the boron transport network in plants. Plant Soil 2014, 385, 1-13. [CrossRef]

34. Wang, S.; Yoshinari, A.; Shimada, T.; Hara-Nishimura, I.; Mitani-Ueno, N.; Feng Ma, J.; Naito, S.; Takano, J. Polar localization of the NIP5;1 boric acid channel is maintained by endocytosis and facilitates boron transport in Arabidopsis roots. Plant Cell 2017, 29, 824-842. [CrossRef] [PubMed]

35. Lu, Y.B.; Qi, Y.P.; Yang, L.T.; Guo, P.; Li, Y.; Chen, L.S. Boron-deficiency-responsive microRNAs and their targets in Citrus sinensis leaves. BMC Plant Biol. 2015, 15, 271. [CrossRef] [PubMed]

36. Gimeno, V.; Simón, I.; Nieves, M.; Martínez, V.; Cámara-Zapata, J.M.; García, A.L.; García-Sánchez, F. The physiological and nutritional responses to an excess of boron by Verna lemon trees that were grafted on four contrasting rootstocks. Trees 2012, 26, 1513-1526. [CrossRef]

37. Hua, T.; Zhang, R.; Sun, H.; Liu, C. Alleviation of boron toxicity in plants: Mechanisms and approaches. Crit. Rev. Environ. Sci. Technol. 2020, 51, 2975-3015. [CrossRef]

38. Wang, N.; Yan, T.; Fu, L.; Zhou, G.; Liu, Y.; Peng, S.A. Differences in boron distribution and forms in four citrus scion-rootstock combinations with contrasting boron efficiency under boron-deficient conditions. Trees 2014, 28, 1589-1598. [CrossRef]

39. Mattos, D., Jr.; Hippler, F.W.R.; Boaretto, R.M.; Stuchi, E.S.; Quaggio, J.A. Soil boron fertilization: The role of nutrient sources and rootstocks in citrus production. J. Integr. Agric. 2017, 16, 1609-1616. [CrossRef]

40. Quaggio, J.A.; Junior, D.M.; Cantarella, H.; Junior, A.T. Boron and zinc application on soil as complement to leaf spray on orange Pera trees. Pesqui. Agropec. Bras. 2003, 38, 627-634. [CrossRef]

41. Quaggio, J.A.; Junior, D.M.; Boaretto, R.M. Sources and rates of potassium for sweet orange production. Sci. Agric. 2011, 68, 369-375. [CrossRef]

42. Bellaloui, N.; Brown, P.H.; Dandekar, A.M. Manipulation of in vivo sorbitol production alters boron uptake and transport in tobacco. Plant Physiol. 1999, 119, 735-742. [CrossRef]

43. Jin, L.F.; Liu, Y.Z.; Yin, X.X.; Peng, S.A. Transcript analysis of citrus miRNA397 and its target LAC7 reveals a possible role in response to boron toxicity. Acta Physiol. Plant 2015, 38, 18. [CrossRef]

44. Zhang, M.; Liu, R.; Liu, H.; Yang, H.; Li, X.; Wang, P.; Zhu, F.; Xu, R.; Xue, S.; Cheng, Y. Citrus NIP5;1 aquaporin regulates cell membrane water permeability and alters PIPs plasma membrane localization. Plant Mol. Biol. 2021, 106, 449-462. [CrossRef] [PubMed]

45. Huang, J.H.; Zhang, L.Y.; Lin, X.J.; Gao, Y.; Zhang, J.; Huang, W.L.; Zhao, D.; Ferrarezi, R.S.; Fan, G.C.; Chen, L.S. CsiLAC4 modulates boron flow in Arabidopsis and Citrus via high-boron-dependent lignification of cell walls. New Phytol. 2021. [CrossRef] [PubMed]

46. Boaretto, R.M.; Quaggio, J.A.; De Assis Alves Mourão Filho, F.; Giné, M.F.; Boaretto, A.E. Absorption and mobility of boron in young Citrus plants. Commun. Soil Sci. Plan 2008, 39, 2501-2514. [CrossRef]

47. Boaretto, R.M.; Quaggio, J.A.; Mattos, D.; Muraoka, T.; Boaretto, A.E. Boron uptake and distribution in field grown Citrus trees. J. Plant Nutr. 2011, 34, 839-849. [CrossRef] 
48. Li, Y.; Han, M.Q.; Lin, F.; Ten, Y.; Lin, J.; Zhu, D.H.; Guo, P.; Weng, Y.B.; Chen, L.S. Soil chemical properties, 'Guanximiyou' pummelo leaf mineral nutrient status and fruit quality in the southern region of Fujian province, China. J. Soil Sci. Plant Nutr. 2015, 15, 263-269. [CrossRef]

49. Landi, M.; Degl'Innocenti, E.; Pardossi, A.; Guidi, L. Antioxidant and photosynthetic responses in plants under boron toxicity: A review. Agric. Biol. Sci. 2012, 7, 255-270. [CrossRef]

50. Chapman, H.D. The mineral nutrition of citrus. In The Citrus Industry, 2nd ed.; Reuther, W., Bachelor, L.D., Webber, H.J., Eds.; University of California Press: Berkeley, CA, USA, 1968; pp. 138-148.

51. Liu, Y.Z.; Li, E.A.; Yang, C.Q.; Peng, S.A. Effects of boron-deficiency on anatomical structures in the leaf main vein and fruit mesocarp of pummelo [Citrus grandis (L.) Osbeck]. J. Hortic. Sci. Biotechnol. 2013, 88, 693-700. [CrossRef]

52. Wimmer, M.A.; Eichert, T. Review: Mechanisms for boron deficiency-mediated changes in plant water relations. Plant Sci. 2013, 203, 25-32. [CrossRef]

53. Landi, M.; Margaritopoulou, T.; Papadakis, I.E.; Araniti, F. Boron toxicity in higher plants: An update. Planta 2019, 250, 1011-1032. [CrossRef]

54. Goldbach, H.E.; Wimmer, M.A. Boron in plants and animals: Is there a role beyond cell-wall structure? J. Plant Nutr. Soil Sci. 2007, 170, 39-48. [CrossRef]

55. Huang, J.H.; Qi, Y.P.; Wen, S.X.; Guo, P.; Chen, X.M.; Chen, L.S. Illumina microRNA profiles reveal the involvement of miR397a in Citrus adaptation to long-term boron toxicity via modulating secondary cell-wall biosynthesis. Sci. Rep. 2016, 6, 22900. [CrossRef] [PubMed]

56. Yang, L.T.; Zhou, Y.F.; Wang, Y.Y.; Wu, Y.M.; Ye, X.; Guo, J.X.; Chen, L.S. Magnesium deficiency induced global transcriptome change in Citrus sinensis leaves revealed by RNA-Seq. Int. J. Mol. Sci. 2019, 20, 3129. [CrossRef] [PubMed]

57. Mittler, R. ROS are good. Trends Plant Sci. 2017, 22, 11-19. [CrossRef]

58. Meng, X.; Chen, W.W.; Wang, Y.Y.; Huang, Z.R.; Ye, X.; Chen, L.S.; Yang, L.T. Effects of phosphorus deficiency on the absorption of mineral nutrients, photosynthetic system performance and antioxidant metabolism in Citrus grandis. PLoS ONE 2021, 16, e0246944. [CrossRef]

59. Zhou, Y.F.; Wang, Y.Y.; Chen, W.W.; Chen, L.S.; Yang, L.T. Illumina sequencing revealed roles of microRNAs in different aluminum tolerance of two citrus species. Physiol. Mol. Biol. Plants 2020, 26, 2173-2176. [CrossRef] [PubMed]

60. Guo, P.; Qi, Y.P.; Cai, Y.T.; Yang, T.Y.; Yang, L.T.; Huang, Z.R.; Chen, L.S. Aluminum effects on photosynthesis, reactive oxygen species and methylglyoxal detoxification in two Citrus species differing in aluminum tolerance. Tree Physiol. 2018, 38, 1548-1565. [CrossRef]

61. Yang, G.H.; Yang, L.T.; Jiang, H.X.; Li, Y.; Wang, P.; Chen, L.S. Physiological impacts of magnesium-deficiency in Citrus seedlings: Photosynthesis, antioxidant system and carbohydrates. Trees 2012, 26, 1237-1250. [CrossRef]

62. Li, Q.; Chen, L.S.; Jiang, H.X.; Tang, N.; Yang, L.T.; Lin, Z.H.; Li, Y.; Yang, G.H. Effects of manganese-excess on $\mathrm{CO}_{2}$ assimilation, ribulose-1,5-bisphosphate carboxylase/oxygenase, carbohydrates and photosynthetic electron transport of leaves, and antioxidant systems of leaves and roots in Citrus grandis seedlings. BMC Plant Biol. 2010, 10, 42. [CrossRef]

63. Noctor, G.; Reichheld, J.P.; Foyer, C.H. ROS-related redox regulation and signaling in plants. Semin. Cell Dev. Biol. 2017, 80, 3-12. [CrossRef]

64. Mukhopadhyay, M.; Ghosh, P.D.; Mondal, T.K. Effect of boron deficiency on photosynthesis and antioxidant responses of young tea plantlets. Russ. J. Plant Physiol. 2013, 60, 633-639. [CrossRef]

65. Simón-Grao, S.; Nieves, M.; Martínez-Nicolás, J.J.; Cámara-Zapata, J.M.; Alfosea-Simón, M.; García-Sánchez, F. Response of three citrus genotypes used as rootstocks grown under boron excess conditions. Ecotox. Environ. Saf. 2018, 159, 10-19. [CrossRef] [PubMed]

66. Sheng, O.; Song, S.; Peng, S.; Deng, X. The effects of low boron on growth, gas exchange, boron concentration and distribution of 'Newhall' navel orange (Citrus sinensis Osb.) plants grafted on two rootstocks. Sci. Hortic. 2009, 121, 278-283. [CrossRef]

67. Liu, G.; Jiang, C.; Wang, Y. Distribution of boron and its forms in young "Newhall" navel orange (Citrus sinensis Osb.) plants grafted on two rootstocks in response to deficient and excessive boron. Soil Sci. Plant Nutr. 2011, 57, 93-104.

68. Tepe, M.; Aydemir, T. Antioxidant responses of lentil and barley plants to boron toxicity under different nitrogen sources. Afr. J. Biotechnol. 2011, 53, 10882-10891.

69. Riaz, M.; Kamran, M.; Fang, Y.; Yang, G.; Rizwan, M.; Ali, S.; Zhou, Y.; Wang, Q.; Deng, L.; Wang, Y.; et al. Boron supply alleviates cadmium toxicity in rice (Oryza sativa L.) by enhancing cadmium adsorption on cell wall and triggering antioxidant defense system in roots. Chemosphere 2021, 266, 128938. [CrossRef]

70. Riaz, M.; Kamran, M.; Rizwan, M.; Ali, S.; Zhou, Y.; Núñez-Delgado, A.; Wang, X. Boron application mitigates Cd toxicity in leaves of rice by subcellular distribution, cell wall adsorption and antioxidant system. Ecotox. Environ. Saf. 2021, $222,112540$. [CrossRef]

71. Wu, X.; Song, H.; Guan, C.; Zhang, Z. Boron mitigates cadmium toxicity to rapeseed (Brassica napus) shoots by relieving oxidative stress and enhancing cadmium chelation onto cell walls. Environ. Pollut. 2020, 263, 114546. [CrossRef]

72. Wu, X.; Song, H.; Guan, C.; Zhang, Z. Boron alleviates cadmium toxicity in Brassica napus by promoting the chelation of cadmium onto the root cell wall components. Sci. Total. Environ. 2020, 728, 138833. [CrossRef]

73. Chen, D.; Chen, D.; Xue, R.; Long, J.; Lin, X.; Lin, Y.; Jia, L.; Zeng, R.; Song, Y. Effects of boron, silicon and their interactions on cadmium accumulation and toxicity in rice plants. J. Hazard. Mater. 2019, 367, 447-455. [CrossRef] 
74. Li, X.W.; Liu, J.Y.; Fang, J. Boron supply enhances aluminum tolerance in root border cells of pea (Pisum sativum) by interacting with cell wall pectins. Front. Plant Sci. 2017, 8, 742. [CrossRef]

75. Heidarabadi, D.M.; Ghanati, F.; Fujiwara, T. Interaction between boron and aluminum and their effects on phenolic metabolism of Linum usitatissimum L. roots. Plant Physiol. Biochem. 2011, 49, 1377-1383. [CrossRef] [PubMed]

76. Yang, L.T.; Liu, J.W.; Wu, Y.M.; Qi, Y.P.; Wang, J.L.; Lai, N.W.; Ye, X.; Chen, L.S. Proteome profile analysis of boron-induced alleviation of aluminum-toxicity in Citrus grandis roots. Ecotox. Environ. Saf. 2018, 162, 488-498. [CrossRef] [PubMed]

77. Zhou, X.X.; Yang, L.T.; Qi, Y.P.; Guo, P.; Chen, L.S. Mechanisms on boron-induced alleviation of aluminum-toxicity in Citrus grandis seedlings at a transcriptional level revealed by cDNA-AFLP analysis. PLoS ONE 2015, 10, e0115485.

78. Wang, L.Q.; Yang, L.T.; Guo, P.; Zhou, X.X.; Ye, X.; Chen, E.J.; Chen, L.S. Leaf cDNA-AFLP analysis reveals novel mechanisms for boron-induced alleviation of aluminum-toxicity in Citrus grandis seedlings. Ecotox. Environ. Saf. 2015, 120, 349-359. [CrossRef] 